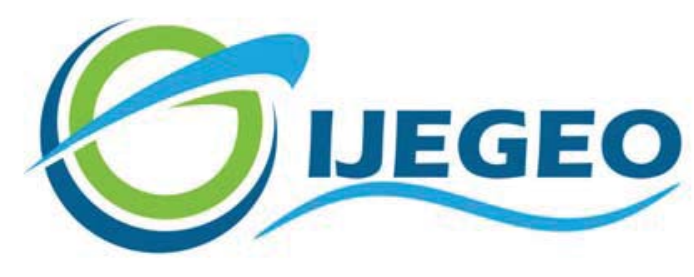

International Journal of Environment and Geoinformatics (IJEGEO) is an international, multidisciplinary, peer reviewed, open access journal.

\title{
Parametric Architectural Elements from Point Clouds for HBIS Applications
}

\section{Cemal Özgür KIVILCIM, Zaide DURAN}

\author{
Chief in Editor \\ Prof. Dr. Cem Gazioğlu \\ Co-Editors \\ Prof. Dr. Dursun Zafer Şeker, Prof. Dr. Şinasi Kaya, \\ Prof. Dr. Ayşegül Tanık and Assist. Prof. Dr. Volkan Demir
}

Editorial Committee (June 2021)

\begin{abstract}
Assoc. Prof. Dr. Abdullah Aksu (TR), Assit. Prof. Dr. Uğur Algancı (TR), Prof. Dr. Bedri Alpar (TR), Assoc. Prof. Dr. Aslı Aslan (US), Prof. Dr. Levent Bat (TR), Prof. Dr. Paul Bates (UK), İrşad Bayırhan (TR), Prof. Dr. Bülent Bayram (TR), Prof. Dr. Luis M. Botana (ES), Prof. Dr. Nuray Çağlar (TR), Prof. Dr. Sukanta Dash (IN), Dr. Soofia T. Elias (UK), Prof. Dr. A. Evren Erginal (TR), Assoc. Prof. Dr. Cüneyt Erenoğlu (TR), Dr. Dieter Fritsch (DE), Prof. Dr. Çiğdem Göksel (TR), Prof.Dr. Lena Halounova (CZ), Prof. Dr. Manik Kalubarme (IN), Dr. Hakan Kaya (TR), Assist. Prof. Dr. Serkan Kükrer (TR), Assoc. Prof. Dr. Maged Marghany (MY), Prof. Dr. Michael Meadows (ZA), Prof. Dr. Nebiye Musaoğlu (TR), Prof. Dr. Masafumi Nakagawa (JP), Prof. Dr. Hasan Özdemir (TR), Prof. Dr. Chryssy Potsiou (GR), Prof. Dr. Erol Sarı (TR), Prof. Dr. Maria Paradiso (IT), Prof. Dr. Petros Patias (GR), Prof. Dr. Elif Sertel (TR), Prof. Dr. Nüket Sivri (TR), Prof. Dr. Füsun Balık Şanlı (TR), Prof. Dr. Uğur Şanlı (TR), Duygu Ülker (TR), Prof. Dr. Seyfettin Taş (TR), Assoc. Prof. Dr. Ömer Suat Taşkın (TR), Assist. Prof. Dr. Tuba Ünsal (TR), Dr. Manousos Valyrakis (UK), Dr. İnese Varna (LV), Dr. Petra Visser (NL), Prof. Dr. Selma Ünlü (TR), Assoc. Prof. Dr. Oral Yağcı (TR), Prof. Dr. Murat Yakar (TR), Assoc. Prof. Dr. İ. Noyan Yılmaz (AU); Assit. Prof. Dr. Sibel Zeki (TR)
\end{abstract}




\title{
Parametric Architectural Elements from Point Clouds for HBIS Applications
}

\author{
Cemal Özgür Kivilcim* (iD) , Zaide Duran (iD
}

Istanbul Technical University, Department of Geomatics Engineering, 34469 Maslak Istanbul, TR

Corresponding Author: C.Ö. Kıvılcım

E-mail: kivilcim@itu.edu.tr

Received: $11 \quad$ Sept 2020

Accepted: $07 \quad$ Dec 2020

How to cite: Kivilcim and Duran (2021). Parametric Architectural Elements from Point Clouds for HBIS Applications, International Journal of Environment and Geoinformatics (IJEGEO), 8(2):144-149. doi: 10.30897/ijegeo.803334

\begin{abstract}
To preserve tangible cultural assets for the future, it is crucial to make sure that the maintenance, repair, and restoration of these buildings are of high quality. To ensure proper cultural heritage preservation, highly accurate measurement and modelling methods are necessary. For this purpose, laser scanner systems are widely used; without any doubt, these systems provide many advantages over conventional measuring techniques. On the other hand, the scan angle, the distance to the object, the object's material composition, the atmospheric conditions, as well as obstacles between the scanner and objects, can cause gaps or noise in the point clouds, making it challenging to manage and interpret the resulting datasets. Thus, extracting the geometries of architectural façade elements from these point clouds is often tedious and requires a high level of expertise. Projects utilizing Building Information Modelling (BIM) Systems have recently begun in Turkey. Although this technology is generally applied to address the whole life cycle of new buildings beginning with the design stage, it is necessary to define existing structures in this system. In this context, research-development and practices related to tangible cultural assets are carried out under the name of the Historic Building Information System (HBIS). In our study, we create parametric models that are needed for transferring the cultural assets, which subject to deformation over years. A semi-automatic methodology based on the RANSAC algorithm was applied to extract geometry from point cloud data that contains noise. The obtained model was transferred to BIM following IFC standards. Şehzade Mosque, built by Mimar Sinan in the 16th century Ottoman Classical Period during the reign of Sultan Suleyman the Magnificent, was chosen as the application area of the study. The architectural elements obtained from the application of the current point clouds were compared with the existing architectural drawings, and the contributions of the study were evaluated.
\end{abstract}

Keywords: Cultural Heritage, Architectural Survey, Point Cloud, 3D Modelling, BIMS

\section{Introduction}

The improvement of methods for surveying historical monuments and sites is an important contribution to recording and perceptual monitoring of cultural heritage, to preservation and restoration of any valuable architectural or other cultural monument, object or site, as a support to architectural, archaeological and other art-historical research (Avsar et al, 2008; Arca et al., 2018). Tangible cultural heritage assets are a reflection of humanity's challenge to distinguish his knowledge, skills, and aesthetics values beyond his time. However, these essential heritage assets suffer deformations and alterations due to human activities and the impacts of the natural environment over time. Therefore, accurate documentation of tangible cultural assets plays a critical role in conservation, preservation, and restoration projects: International treaties and organizations such as UNESCO, as well as regional and national enforcement, reflect this importance.

Metric-based survey and 3D model products play a vital role in conservation, restoration, and maintenance projects. Figure 1. Geospatial Data/Information Management for Cultural Heritage shows the complete geospatial data/information management pipeline for cultural heritage documentation, conservation, and restoration projects (Kivilcim, 2009; Seker, et al., 2010).
Due to their accurate and robust systems, laser scanning technologies have become one of the major developments for geospatial data acquisition in this field. With the recent advances in consumer-grade costs / efficiency and computational capacity/performances, laser-scanning systems have become prominent among different user communities and gained acceptance in applications of the cultural heritage domain for documentation. However, in real-world examples, the project workflow relies on the interpretation and the diligent work of experts, which is costly and open to human error. Point cloud data is used mostly for visualization and manual plotting. Various research groups from geomatics, computer vision, and graphics are working towards a fully automated 3D building modelling solution using point clouds.

On the other hand, the Architecture, Engineering, and Construction (AEC) industry is in transition with Building Information Modelling (BIM). BIM is a methodology that presents more than geometry and design model. It includes physical and functional characteristics of the building structure, semantic information for various possible usages, and capabilities related such as HVAC, energy efficiency, structural assessment. BIM provides a collaborative working environment where any change in design is 
automatically reflected through the entire project, thus giving the possibility to experts and stakeholders to work in a seamless environment.

Building modeling from the point cloud is a three-step process, including; detection, reconstruction, and, attribution. Most commercially available applications used for building modelling from the point cloud require manual editing. Yet, applications in cultural heritage documentation and modelling examples are less common; (Demir, 2017) reports no fully automated systems are available for building extraction from the point cloud.

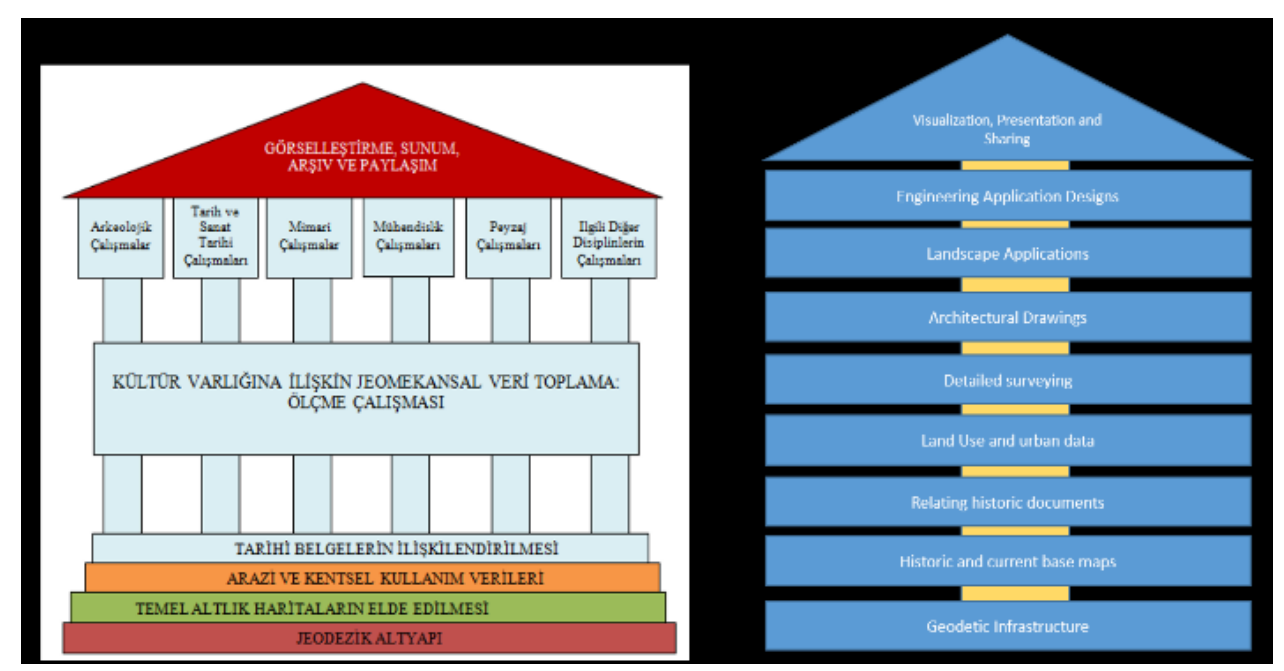

Figure 1. Geospatial Data/Information Management for Cultural Heritage Documentation, Conservation and Restoration Projects (Kivilcim, 2009).

As-built documentation and BIM applications for existing structures have increased in recent years; some countries such as Canada and UK have already implemented regulations for the maintenance and restoration of the cultural heritage assets that require BIM methodology (Arayici et al., 2017). To provide data exchange among user groups and different commercial BIM software, an open data exchange format called Industry Foundation Class (IFC) is used.

One of the first implementations of BIM for buildings was by (Arayici, 2008). Following this, (Murphy et al., 2009) used existing drawings to create parametric architectural libraries and map them on laser scan data, under the term Historic BIM. However, these methods are limited in their ability to account for the deformations and changes that occur in built structures over time. Besides, existing approaches focus on extracting simple primitive objects or modelling objects based on well-documented architectural knowledge for preserved buildings.

The use of HBIS based work extends to various important analyze and knowledge visualization such as structural analysis (Barazzetti et al. 2015) and decay analyze (Chiabrando et al., 2017). Bruno, De Fino, and Fatiguso (Bruno, De Fino, and Fatiguso, 2018) give an extensive review of the HBIS applications and categorize the gaps in current BIM trends toward HBIS Management using a diagnosis-aided approach.

In our study, we applied a RANSAC based semiautomated point cloud segmentation and transferred the extracted geometry using IFC format for BIM. We demonstrate the extracted geometric shapes from our case study and compared them to expert drawn products.

\section{Material and Methods Study Area}

The Şehzadebaşı Mosque in Istanbul was selected as a study area. Built-in 1548 by Architect Sinan, for Sultan Suleyman the Magnificent's son who died at an early age, Şehzadebaşı Mosque had a significant influence on mosque design during the Ottoman Era. Şehzade Mosque has a symmetrical layout plan, with an elegant distribution of domes and arches, and a central dome around 18 meters' radius and 37 meters height carried by four elephant pillars. This mosque design schema was also replicated in other historic mosques such as Sultan Ahmet Mosque (1609) and has a strong influence on modern era mosques in Turkey. Figure 2 shows the location of the mosque in the Historic Peninsula of Istanbul.

\section{Data Used}

For our study, existing datasets, containing both airborne and terrestrial laser scan campaigns acquired from the Istanbul Metropolitan Municipality (IMM), were used. The LIDAR scan campaigns, not only to focus on individual buildings but also on the built and non-built areas of Istanbul. The average point density for the Şehzade Mosque complex area was $15 \mathrm{pts} / \mathrm{m}^{2}$. The reported accuracy of the airborne LIDAR point cloud is under $5 \mathrm{~cm}$ in horizontal and under $10 \mathrm{~cm}$ vertical. Also, 530 terrestrial scans were taken for the documentation survey-campaign, with RIEGL VZ-400. The nominal accuracy of the scanner measurement has an accuracy of $5 \mathrm{~mm}$ and $3 \mathrm{~mm}$ precision at $100 \mathrm{~m}$ range according to the technical specifications. All the data received were delivered georeferenced in the national coordinate system. The advantage of using the laser point cloud 
from different platforms is to minimize the gaps in the

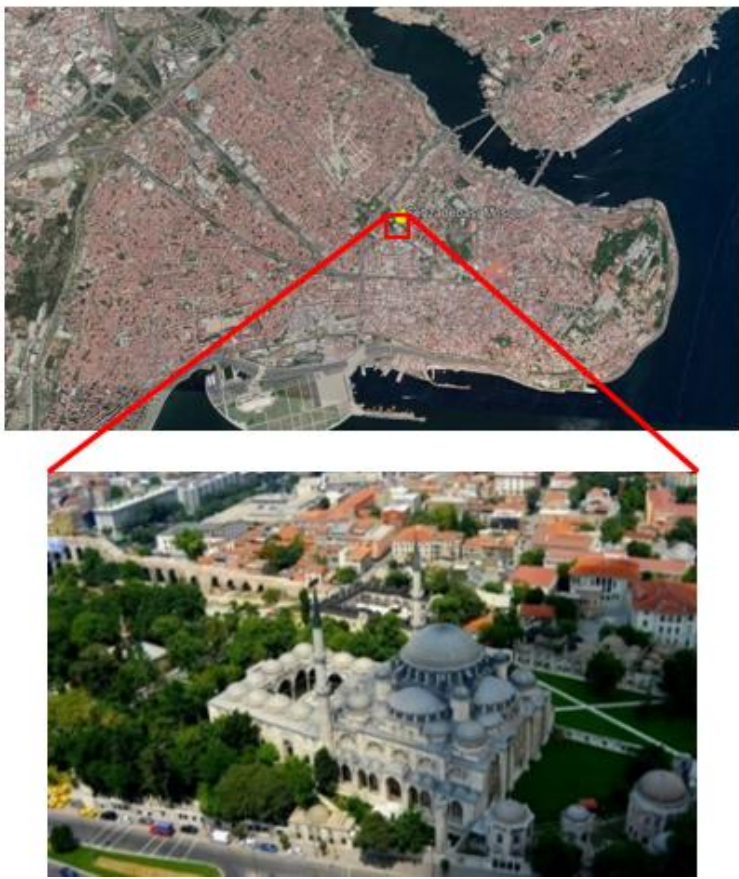

Figure 2. Location of Şehzade Complex in Historic Peninsula of Istanbul.

\section{Methodology}

RANdom SAmple Consensus (RANSAC) algorithm introduced by (Fischler and Bolles, 1981) is an efficient algorithm that is widely used in computer vision for detecting simple shapes both in $2 \mathrm{D}$ and $3 \mathrm{D}$ noisy point clouds. It is reported that it can return successful results compare to similar algorithms even in cases where the outliers ratio is higher than $50 \%$. It is important that the segmentation area should be defined as input since RANSAC would only work within different model elements.

In the literature, RANSAC is used to extract shapes such as spheres, cylinders, and planes from point clouds. Especially, RANSAC is a useful method for the detection of planar roof surfaces (Gonultas et al., 2020; Atik et al., 2018). Similar to our previous work (Kivilcim and Duran, 2016; Büyüksalih et al., 2019; Büyüksalih and Gazioğlu, 2019), we applied a RANSAC based methodology for extracting the domes of the mosque. In general, the steps of our method for geometrical model extraction from noisy point cloud were as follows:

- User Input: the point cloud

- User Input: Selection of the primitive shape model

- $\quad$ Pick n random points based on the model

- Check preconditions: coplanarity/ colinearity based on model condition

- Estimate model

- Test the model, compare it to the previous best model

- Based on the outputs, return the parametric object properties, dome center and radius, point cloud.

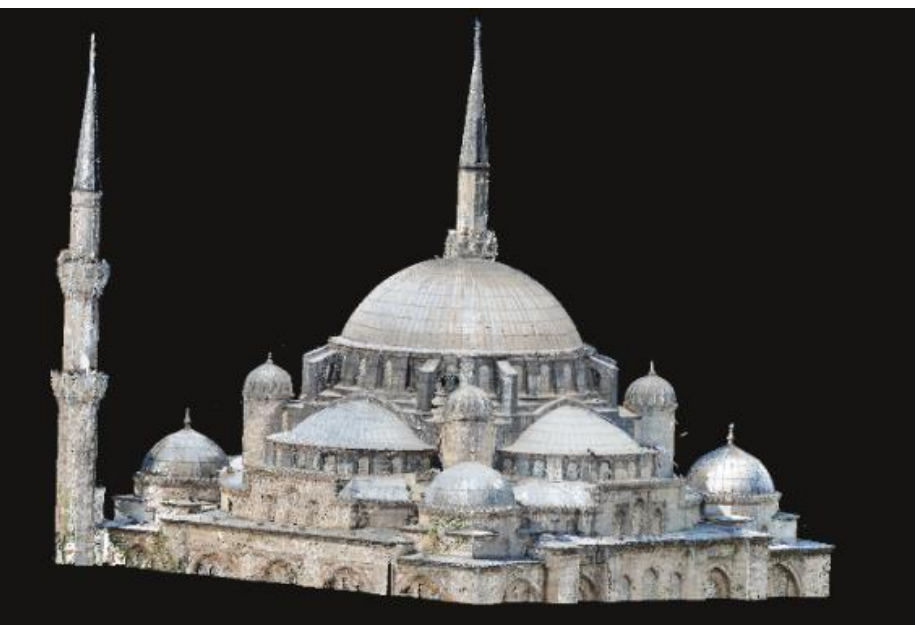

Figure 2. View from RGB color-coded point cloud.

inlier/outlier point data, and the success rates or select a new candidate.

We implemented RANSAC method by using the formula given in equation (1) to determine the maximum number of iteration $(\mathrm{N})$, where (s) size of the sample set, (e) is the outlier ratio, (p) is the probability of no outliers is selected as 0.99 conventionally.

$$
\mathrm{N}=\log (1-\mathrm{p}) / \log \left(1-(1-e)^{\mathrm{S}}\right)
$$

In practice, the outlier ratio e is almost unknown a priori; therefore computations can start based on worst case possibility such as $\% 50$ of outlier ratio and, the algorithm can be adapted as more inliers are found. In our application, we considered this fact since the point cloud datasets have an unknown inlier ratio vs. the primitive models as given in (Hartley and Zisserman, 2004).

$$
\mathrm{N}=\infty \text {, sample_count }=0
$$

While $\mathrm{N}>$ sample_count, choose a sample and count the number of inliers. Set $\mathrm{e}_{0}=1-$ (number of inliers) / (total number of points). If $\mathrm{e}_{0}<\mathrm{e}$ Set $\mathrm{e}=\mathrm{e}_{0}$ and recompute $\mathrm{N}$ from e.

In Figure 4 image of the exemplary point cloud from the study area is given, colored according to the scan type used.

For establishing the candidate model, a sphere in $\mathrm{R}^{3}$ euclidean space center coordinates of a sphere $\left(\mathrm{x}_{0}, \mathrm{y}_{0}, \mathrm{z}_{0}\right)$ and each point $(\mathrm{x}, \mathrm{y}, \mathrm{z})$ satisfy the basic equation (3).

$$
\left(\mathrm{x}-\mathrm{x}_{0}\right)^{2}+\left(\mathrm{y}-\mathrm{y}_{0}\right)^{2}+\left(\mathrm{z}-\mathrm{z}_{0}\right)^{2}=\mathrm{r}^{2}
$$


At least four linearly independent equations determine the four unknowns of a sphere (radius and center coordinates); hence our script checks the selected four points to be non-coplanar, hence is enough to solve the unknowns with the determinant.

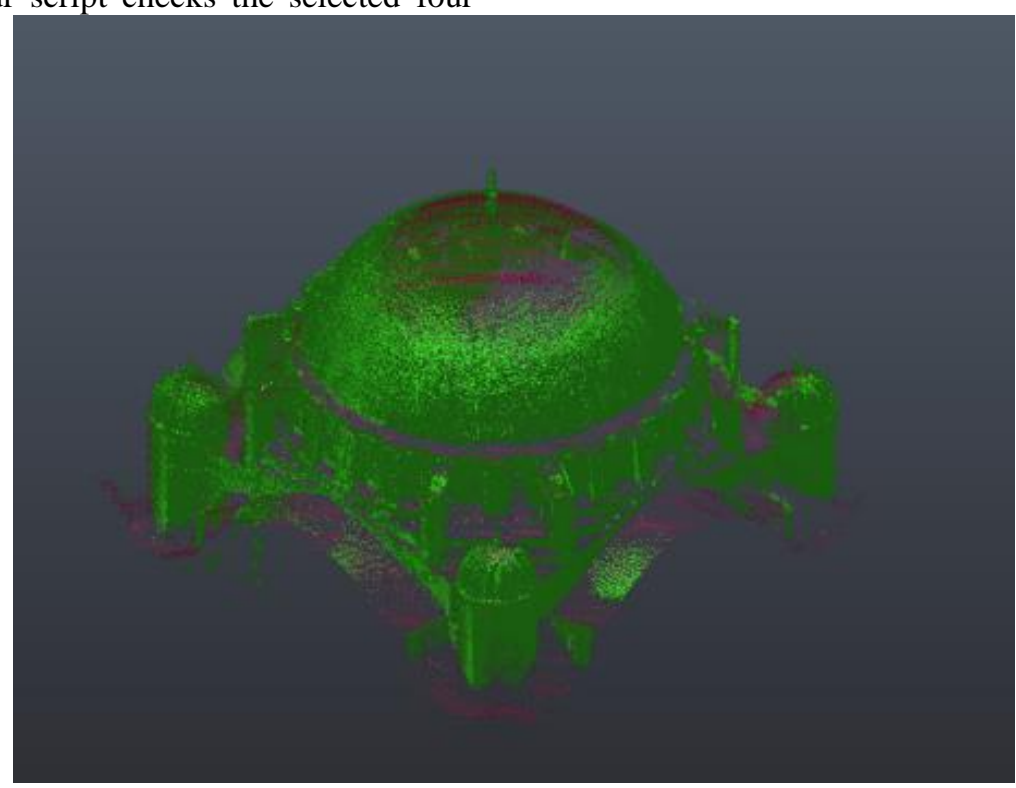

Figure 4. Point cloud colored based on the scanner source (aerial and terrestrial).

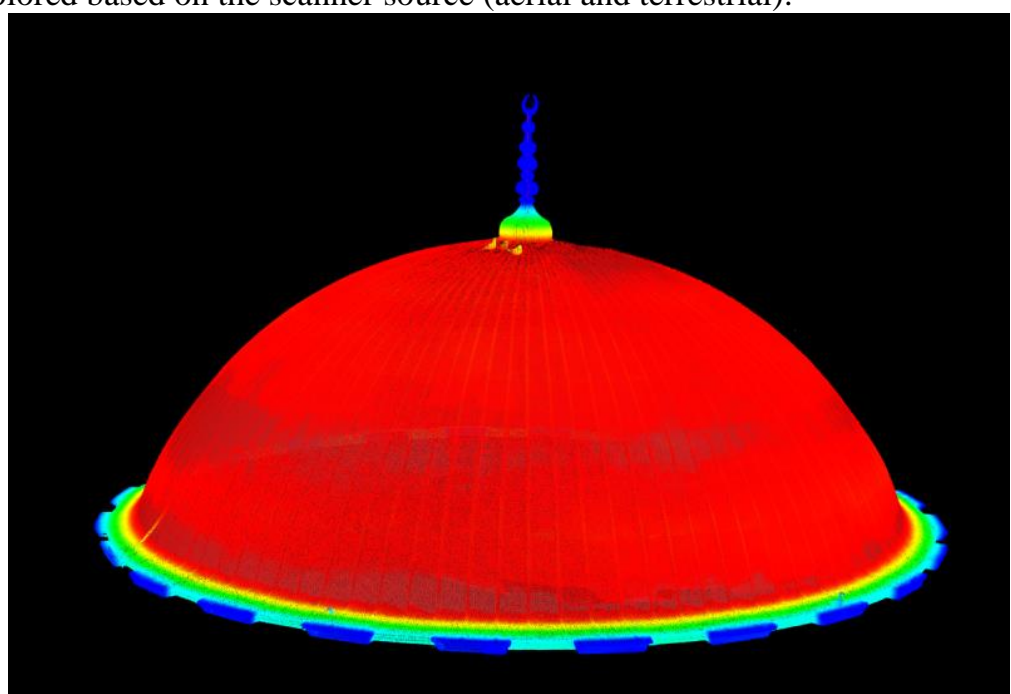

Figure 5. The distance of each point to the extracted parametric dome. Red Color indicates the closest blue the furthest.

\section{Results and Discussion}

The implementation was coded with Python and, the visualizations were carried out using VTK. Following the extraction of the parametric objects, the results were exported to FreeCAD using its python module and handled in Autodesk Revit using IFC export/import modules.

We made our initial test of our applications with a consumer-grade laptop with a quad-core Intel i7 5th generation processor with 8 GB RAM, running Windows 10. While the processing time for the applications was only a few minutes level. The final outputs of the algorithm of tested domes and relevant information on iteration number and ratio of inliers are given in Table 1.

Table 1. Results of RANSAC based segmentation process with best model iteration sequence and the ratio of inliers to the given point cloud for main and semidomes of Şehzade Mosque.

\begin{tabular}{ccc}
\hline Dome Name & $\begin{array}{c}\text { Best Iteration } \\
\text { Sequence }\end{array}$ & $\begin{array}{c}\text { Ratio of } \\
\text { inliers }\end{array}$ \\
\hline Central Dome & 8 & 0.85 \\
NW Semi-dome & 4 & 0.85 \\
SE Semi-dome & 6 & 0.81 \\
SW Semi-dome & 8 & 0.79 \\
NE Semi-dome & 8 & 0.81 \\
\hline
\end{tabular}

In figure 5, we present the distance of each point to the parametric dome. Red indicates the closest distance to the parametric shape.

In the final; the conservation expert drawn cross-sections were compared to the produced sphere parameters. The overlay of the dome element with its thickness from the architectural survey and our test result shows a closefitting in Figure 6. The overall distance between the expert drawn and parametric shape was found under $3 \mathrm{~cm}$ for this example. The final exported geometry as an IFC file is given in Figure 7. 


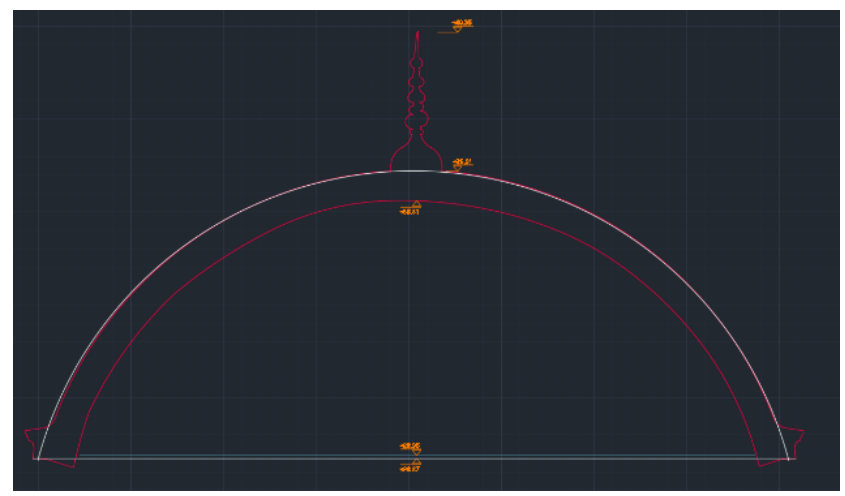

Figure 6. An example of comparison: Overlay of extracted South East Facade Cross-section (red) and the dome parameters from methodology (white).

Integration of HBIS methodology with point cloud-based data acquisition techniques (Scan to BIM) is an important step for cultural heritage related works. Application of our methodology and the results presented is a practical step working in the noisy point cloud using RANSAC based methodology. Our study showed few differences in $\mathrm{cm}$ between the expert drawings and extracted models from our method. We would like to extend our work to further details and local variations in dome elements and also apply to other architectural elements including ornaments such as skirts and spire of the dome and enrich with further semantic data.

Furthermore, integration with machine learning to extract geometric and semantic information for HBIS will be an important step towards a fully automated solution. Also, open-source HBIS approaches such as those presented in (Murphy et al., 2017) and international initiatives are needed for the practical applications of HBIS.

Our approach presents a coarse to fine modeling strategy from point cloud to HBIS oriented applications. In our work we rasterized the point cloud and extracted contour lines then various checks on each closed contour line was applied to detect possible dome structures. We successfully extracted dome contour lines matching the mosque dome layout and created a search-space for the application of points that represent the models.

The outputs of our method can be used for various levels of BIM as shown in Hata! Başvuru kaynağı bulunamadı, the conservation specialist is flexible to make changes on the final detailed model of the building elements directly on the point cloud and harmonize his/her interpretation with the extracted underlying geometry. It provides an easy interpretation of the structural changes that occurred due to natural and physical loads and material decays based on major changes on dome elements. On the other hand, our method has some limitations, such as the quarter dome structures were not recognized.

In future work, would like to focus on extracting finer details and any possible damaged or altered editions of a

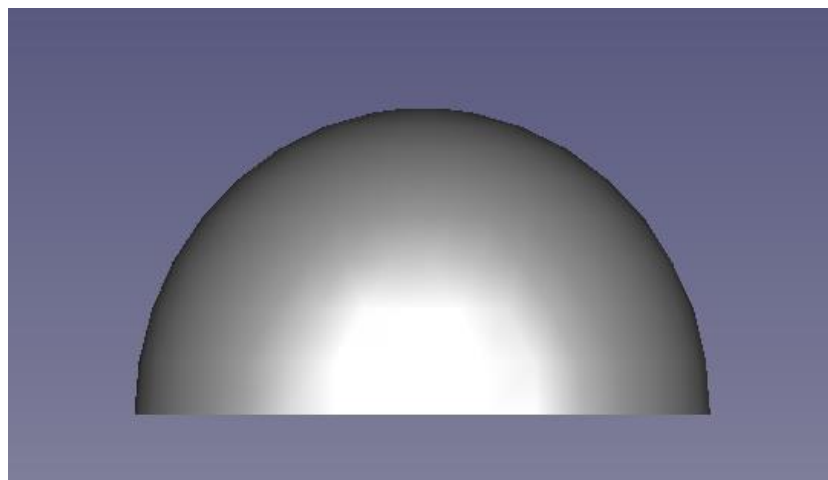

Figure 7. The final output parametric dome geometry ready for BIM application.

cultural asset. One further direction is to develop this methodology to extract the interior models of this mosque and compare them with the results obtained from this paper. We would also like to extend our work for other architectural elements and their variations to other variations of, not only Sinan's but also later derivations of Ottoman mosque designs and other buildings that use domes.

\section{References}

Atik, M. E., Donmez, SO., Duran, Z., Ipbuker, C. (2018). Comparison of Automatic Feature Extraction Methods for Building Roof Planes By Using Airborne LIDAR Data And High-Resolution Satellite Image. Proceedings Book of ICCGIS 2018, Bulgaria.

Arayici, Y., Counsell, J., Mahdjoubi, L., Nagy, G. A., Hawas, S., and Dweidar, K. (Eds.). (2017). Heritage building information modelling. Ed. 1. New York, NY: Routledge.

Arayici, Y. (2008). Towards Building Information Modeling for Existing Structures. Structural Survey 26 (3): 210-22. doi:10.1108/02630800810887108.

Arca, D., Seker, D., Alkan, M., Karakıs, S., Bayık, C., Acar, H. (2018). Development of Web-Based GIS for the Cultural Heritage of Safranbolu, Turkey. International Journal of Environment and Geoinformatics, 5(3), 368-377.doi. 10.30897/ ijegeo.457184.

Avsar, E.O., Duran, Z., Akyol, O., Toz, G. (2008). Modeling of the temple of Apollo Smintheus using photogrammetry and virtual reality. 21st ISPRS International Congress for Photogrammetry and Remote Sensing; Beijing; China; Vol. 37, Pages 357-360.

Barazzetti, L., Banfi, F., Brumana, R., Gusmeroli, G., Previtali, M., Schiantarelli, G. (2015). Cloud-toBIM-to-FEM: Structural simulation with accurate historic BIM from laser scans. Simulation Modelling Practice and Theory, 57, 71-87. doi:10.1016/j.simpat.2015.06.004.

Bruno, S., De Fino, M., and Fatiguso, F. (2018). Historic Building Information Modelling: performance assessment for diagnosis-aided information modelling and management. Automation in 
Construction, $\quad 86, \quad 256-276$. doi:10.1016/j.autcon.2017.11.009.

Büyüksalih, İ., Gazioğlu, C. (2019). New Approach in Integrated Basin Modelling: Melen Airborne LIDAR. International Journal of Environment and Geoinformatics, 6 (1), 22-32.doi. 10.30897/ ijegeo.530272.

Büyüksalih, İ., Alkan, M., Gazioğlu, C. (2019). Design for 3D city model management using remote sensing and GIS: A case study for the Golden Horn in Istanbul, Turkey, Sigma 37 (4), 1447-1462

Chiabrando, F., M. Lo Turco, F. Rinaudo. (2017). Modeling the Decay in an HBIS Starting From 3D Point Clouds. a Followed Approach for Cultural Heritage Knowledge. ISPRS - International Archives of the Photogrammetry, Remote Sensing and Spatial Information Sciences XLII-2/W5 (September): 60512. doi:10.5194/ISPRS-archives-XLII-2-W5-6052017.

Demir, İlke. (2017). A Generalized Proceduralization Framework For Urban Models With Applications In Procedural Modeling, Synthesis, And Reconstruction. Purdue University.

Fischler, M. A. and Bolles, R. (1981). Random Sample Consensus: A Paradigm for Model Fitting with Applications to Image Analysis and Automated Cartography. Communications of the ACM 24 (6): 381-95. doi:10.1145/358669.358692.

Gonultas, F., Atik, M.E., Duran, Z. (2020). Extraction of Roof Planes from Different Point Clouds Using RANSAC Algorithm. International Journal of Environment and Geoinformatics (IJEGEO), 7(2): 165-171. DOI: $10.30897 /$ ijegeo.715510

Hartley, R. and Zisserman A. (2004). Multiple View Geometry in Computer Vision, 2nd Ed. Cambridge UK Cambridge Univ Press.

Kivilcim, C., and Z. Duran. (2016). A Semi-Automated Point Cloud Processing Methodology for 3D Cultural Heritage Documentation. International Archives of the Photogrammetry, Remote Sensing and Spatial Information Sciences - ISPRS Archives 41 (July): 293-96. doi:10.5194/isprsarchives-XLI-B5-2932016.

Kıvılcım, C. (2009). Taşınmaz Kültür Varlıklarının Belgelendirilmesinde Jeomekansal Veri/Bilgi Yönetimi. Istanbul Technical University. Master Thesis.

Murphy, M, A Corns, J Cahill, K Eliashvili, A Chenau, C Pybus, R Shaw, G Devlin, A Deevy, L TruongHong. (2017). Developing Historic Building Information Modeling Guidelines and Procedures for Architectural Heritage in Ireland. XLII (September): 539-46. doi:10.5194/isprs-archives-XLII-2-W5-5392017.

Murphy, M., Eugene M., Sara Pavia. (2009). Historic Building Information Modeling (HBIM). Structural Survey 27 (4). Emerald Group Publishing Limited: 311-27. doi:10.1108/02630800910985108.

Seker, D.Z.; Alkan, M.; Kutoglu, H.; Akcin, H.; Kahya, Y. (2010). Development of a GIS Based Information and Management System for Cultural Heritage Site; Case Study of Safranbolu. In Proceedings of the FIG
Congress 2010, Sydney, Australia, 11-16 April 2010; Number 1-10. 